\title{
Response of tuberculous stricture to antituberculous treatment
}

\author{
B S ANAND, R NANDA, AND G K SACHDEV \\ From the Department of Gastroenterology, G B Pant Hospital, New Delhi, India
}

SUMmaRY Tuberculous infection of the gastrointestinal tract results in a variety of histopathological lesions. Some patients develop intestinal strictures and present with subacute intestinal obstruction. The treatment is controversial and vary from a trial of antituberculous drugs to early surgery: the response to medical therapy is not clear. To examine this issue the present prospective therapeutic trial was carried out on 39 patients with symptoms of bowel obstruction and radiological evidence of intestinal stricture. All patients were treated with conventional antituberculous drugs (streptomycin, rifampicin, and isoniazid) under close supervision. Thirty four $(87 \%)$ patients completed the trial, five were lost to follow up. Thirty one $(91 \%)$ of these showed significant clinical improvement: 26 became completely symptom free, while the remaining five complained of only vague abdominal discomfort. Only three $(8 \%)$ patients failed to respond to treatment and were subjected to surgery. Barium series were repeated in 23 of 31 who completed the treatment; the remaining eight refused further investigations. Complete resolution of the radiological abnormality was seen in $16(70 \%)$ patients. In the remaining seven $(30 \%)$ the stricture persisted; in two of these the treatment was continued for another year and both showed substantial radiological improvement. It is concluded that most patients with tuberculous strictures respond well to medical treatment and surgery should be resorted to only if drug therapy fails.

Despite advances in public health tuberculosis of the gastrointestinal tract remains a common disease in the underdeveloped world. ${ }^{1-3}$ Even in developed countries where there is a marked reduction in this infection, abdominal tuberculosis is not uncommon. ${ }^{+t}$ In a recent report from the UK the number of patients with abdominal tuberculosis admitted in a district general hospital in London over a 10 year period (1973-83) was very similar to those with Crohn's disease $(90 v 102) .^{7}$ This was largely because of the arrival of Asian immigrants although the disease still occurs in the indigenous population. ${ }^{\circ 7}$ With the introduction of potent antituberculous drugs it is now possible to treat most forms of abdominal tuberculosis. The response to treatment of the stenotic variety of intestinal tuberculosis, however, is controversial. Some workers recommend medical treatment ${ }^{\mathrm{x}}$ while others favour surgery in the belief that once a stricture develops it is

Address for correspondence: Professor B S Anand. Department of (iastroenterology. (; B Pant Hospital. New Delhi. $110(102$. India.

Received for publication 5 June 1987 unlikely to open up." "This issue has not been properly examined, however, and consequently this prospective study was carried out on patients presenting with an intestinal stricture and symptoms of subacute intestinal obstruction.

\section{Methods}

PATIENTS

Thirty nine patients were included in the study. Criterion for inclusion was the presence of a stenotic lesion involving one or more areas of the gastrointestinal tract. Patients with unequivocal dilatation of the bowel loops but in whom a definite narrowed segment could not be identified were also included in the study (Fig. 1); in these patients the site of narrowing was considered as just distal to the dilated segment of the bowel. Patients with history suggestive of intestinal obstruction who on barium examination showed only mucosal abnormalities in the form of oedema, irregularity or ulcerations but without any clear cut stricture formation were not included in the study. 
TREATMENT AND FOLLOW UP

Antituberculous treatment was started as soon as the diagnosis was made. The usual drug regimen consisted of streptomycin $1 \mathrm{~g}$ per day, rifampicin $450 \mathrm{mg}$ per day and isoniazid $300 \mathrm{mg}$ per day. After 90 days streptomycin was stopped and the patient was maintained on the remaining two drugs for at least one year.

If drug reaction occurred it was replaced by ethambutol $800 \mathrm{mg}$ per day for the remaining duration of the treatment. Patients were seen once a month and the clinical findings were recorded. Barium studies were repeated after one year of treatment. In two patients, the treatment was continued for another year and the barium study was again repeated.

\section{Results}

The mean (SD) age of the 39 patients was 33.4 (15.1) years (range 11-70 years), consisting of 25 men and 14 women $(\mathrm{M}: \mathrm{F}=1 \cdot 78)$.

Radiographic evidence of pulmonary tuberculosis was obtained in $11(28 \%)$ of 39 patients. On the basis of barium studies the site of involvement was duodenum in one $(2.5 \%)$ patient, small intestine 15 $(38 \%)$, ileocaecal region $10(26 \%)$, colon nine $(23 \%)$, and multiple areas of involvement four $(10 \%)$. The mean (SD) duration of symptoms before presentation was $24.4(33.3)$ months (range 1 month-11 years), with the majority ( 22 of $36 ; 61 \%$ ) of patients presenting within 18 months of the onset of symptoms; in three patients the exact duration of illness could not be ascertained.

CI.INICAI. PROFILE

The most frequent symptoms were abdominal pain and weight loss seen in $36(92 \%)$ patients each; of the three patients without any abdominal discomfort two had painless diarrhoea and one weight loss. Thirty four $(87 \%)$ patients had typical features of bowel obstruction in the form of abdominal pain, distension, and vomiting. Diarrhoea occurred in $12(30 \%)$ patients and in four of these the stools contained blood and mucus.

\section{RESPONSE TO TREATMENT}

\section{Clinical response}

Thirty four $(87 \%)$ of the 39 patients completed the study, the remaining five were lost to follow up. Three $(9 \%)$ of these 34 patients required an emergency operation; resection of the involved segment with end-to-end anastomosis was carried out after an episode of intestinal obstruction in each patient. All three patients made an eventful recovery. The remaining $31(91 \%)$ patients showed

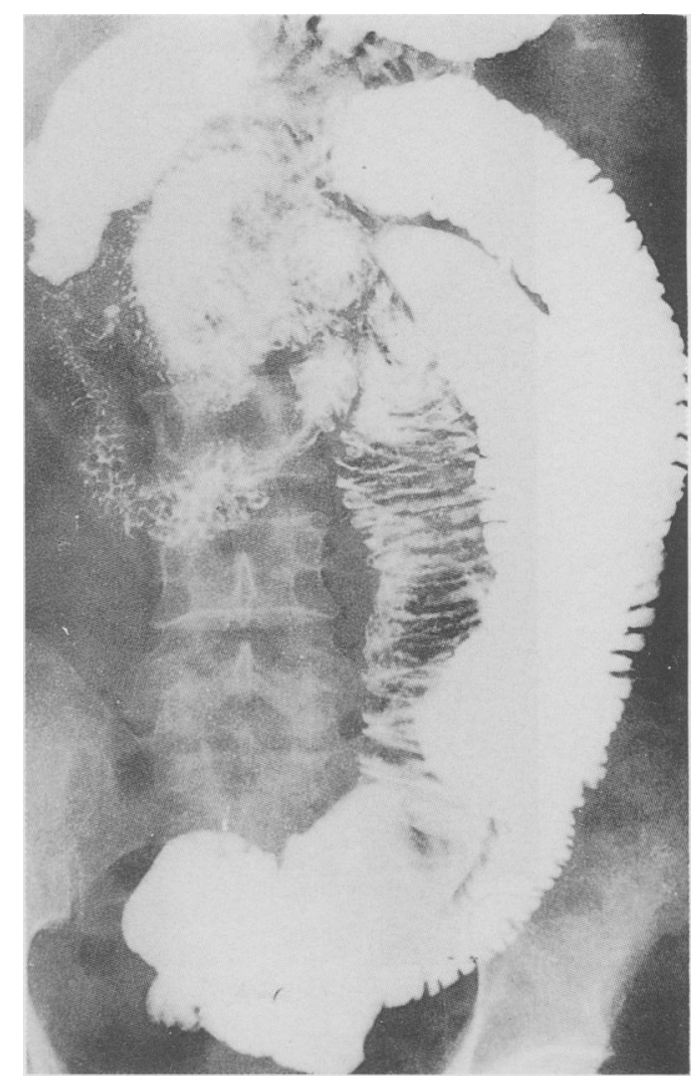

Fig. 1 Barium meal examination of the small bowel showing gross dilatation of the bowel loops but without any clear cut area of stricture formation.

significant clinical improvement; 26 became completely symptom free while five complained of vague abdominal symptoms not requiring medication. Two of these five patients in addition developed one episode each of subacute intestinal obstruction. In both patients the episode occurred six months after they had completed a full course of antituberculous treatment. Both patients recovered on conservative treatment and have remained symptom free for a period of four months and six months respectively.

The mean (SD) time required for cessation of symptoms was $6 \cdot 3( \pm 2 \cdot 2)$ months. Most patients needed three to nine months for full clinical recovery although symptoms such as anorexia, fever and weight loss improved within two months in the majority of patients.

\section{Radiological response}

Barium series were repeated in 23 of the 31 patients who completed a full one year course of treatment, 


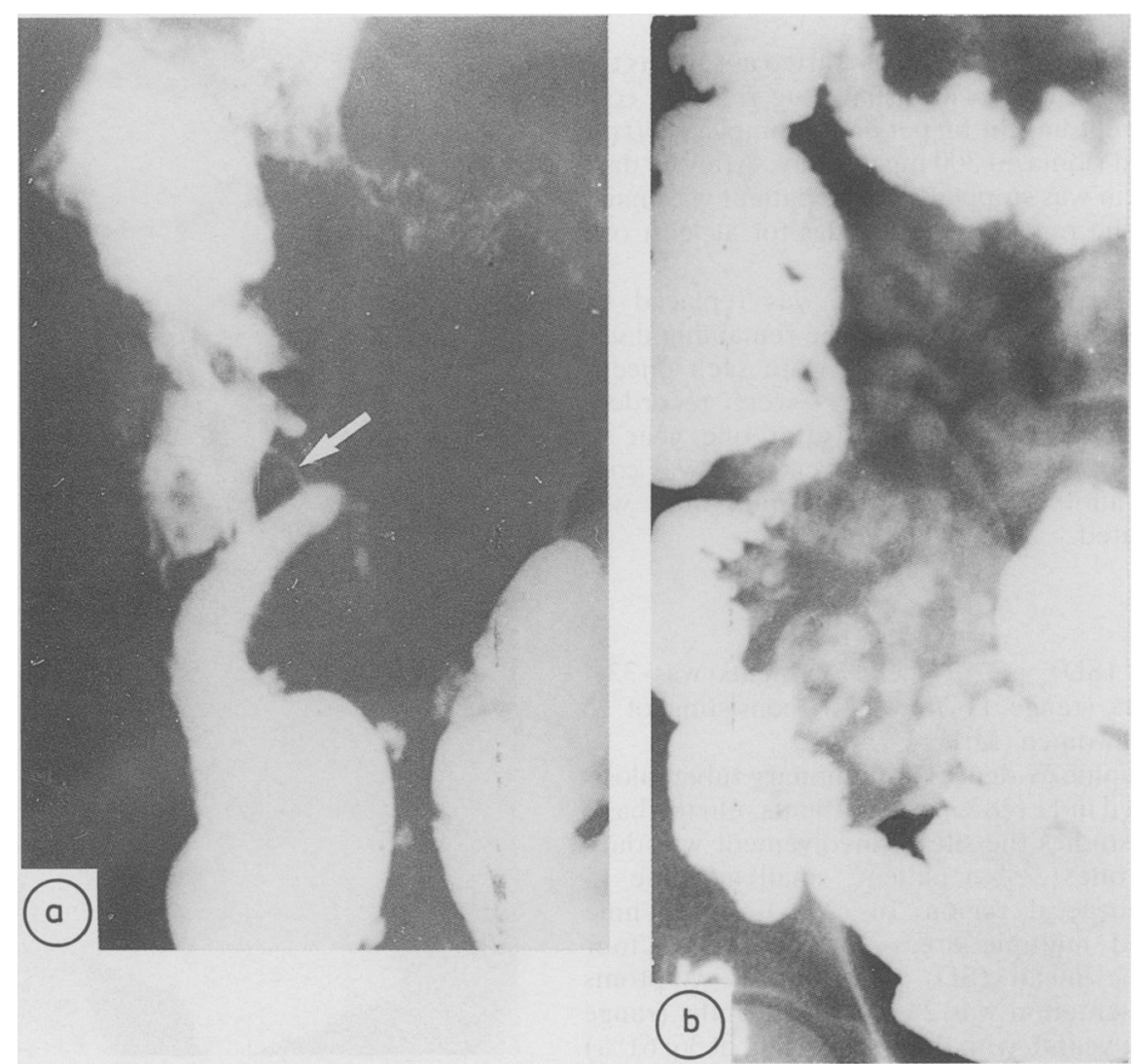

Fig. 2 (a) Marked deformity of the ileocaecal region. Terminal ileum is dilated, the caecum is deformed and the opening of the ileum into the caecum is reduced to a tight stricture (arrow). Total length of the radiological abnormality was $16 \mathrm{~cm}$.

(b) Complete recovery after one year's treatment.

the remaining eight refused further investigations. Sixteen $(70 \%)$ of the 23 showed complete resolution of the radiological abnormality (Figs 2,3 ). In the remaining seven $(30 \%)$ the stricture persisted (Fig. 4 ) and in one of them the deformity became worse (Fig. 5). In two of these seven patients the antituberculous drugs were continued for another one year and the barium study was again repeated. Both patients showed substantial radiological improvement after another year of treatment (Fig. 6).

The clinical details of the 16 patients who recovered radiologically after one year of treatment were compared with the seven who did not (Table). Patients with persisting radiological defect were more often women, were younger, and had a longer duration of symptoms compared with those with a good radiological response. None of these parameters, however, were statistically significant. The response to treatment was not influenced by the site of involvement. Moreover, there was no difference in the clinical response to antitubercular treatment between the two groups; five $(71 \%)$ of the seven non-responders became completely symptom free compared with $14(87.5 \%)$ of 16 who showed a good radiological response. One patient in each group developed an episode of subacute intestinal obstruction after completing the antituberculous treatment.

Comparison of the length of the radiological defect as seen on barium examination was made between the responders and non-responders (Table). Accurate measurements could be obtained in only eight patients in the responder group and in six patients in the non-responder group. Four $(87 \%)$ of the six non-responders had stricture lengths of $12 \mathrm{~cm}$ or more compared with only one $(12.5 \%)$ of eight in the responder group. Patients with multiple strictures (four) responded less well to treatment; one of these 


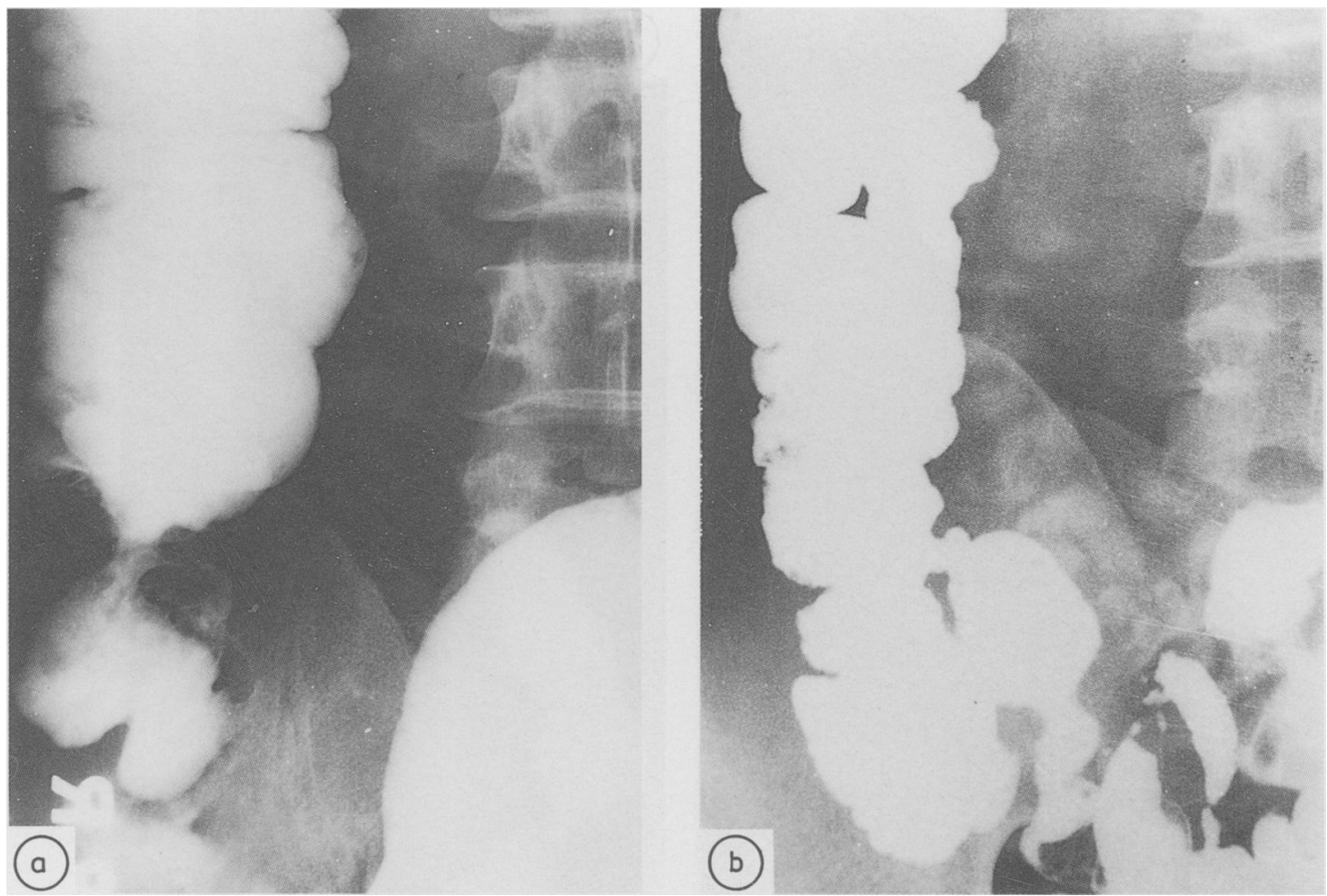

Fig. 3 (a) Tight stricture at the junction of the caecum and ascending colon. (b) Complete recovery after one vear's treatment.

patients required surgery, while in the remaining three the stricture persisted although all three were clinically asymptomatic.

\section{Discussion}

It is usually not possible to make an unequivocal diagnosis of intestinal tuberculosis. The presence of pulmonary tuberculosis ( 11 of $39 ; 28 \%$ in the present study) certainly suggests but does not confirm this possibility. Biopsy specimens obtained from the involved area, may provide the diagnosis, ${ }^{1 i-1.3}$ but it is important to identify acid fast bacilli as similar granulomatous lesions are seen in Crohn's disease. Histological examination of a resected specimen is likely to be more useful but may not always resolve the issue because in the absence of a caseating lesion or acid fast bacilli the possibility of Crohn's disease cannot be completely excluded. ${ }^{14}$ Indeed in a large series from India, caseation was seen in only $10 \%$ patients with ileocaecal tuberculosis. ${ }^{15}$ Moreover, the detection rate of acid fast bacilli is also not very high, with differing reports of $6 \%,{ }^{16} 22 \%,{ }^{17}$ and $58 \%$. ${ }^{18}$
Therefore in countries where tuberculosis is still endemic the diagnosis is usually presumptive and a therapeutic trial with antituberculous drugs is the most rewarding diagnostic procedure. ${ }^{19}$

The modern antituberculous drugs are extremely effective but their role in the presence of a stenotic lesion of the bowel is controversial. Some workers have found that the intestinal lesions revert to normal after therapy. ${ }^{2122}$ These observations were made when streptomycin was first introduced in the treatment of tuberculosis. More recently, however, it has been suggested that healing may lead to further narrowing of the bowel lumen. ${ }^{2: 225}$ Indeed the very effectiveness of the modern chemotherapeutic agents such as rifampicin is blamed for an increase in the incidence of cicatrisation and obstruction.' These observations have led some workers to recommend that once symptoms of bowel obstruction appear antituberculous drugs are of little use and surgery is unavoidable." "1" $=0$

In the present study, 34 patients with unequivocal clinical and/or radiological evidence of intestinal obstruction were maintained under close observation 


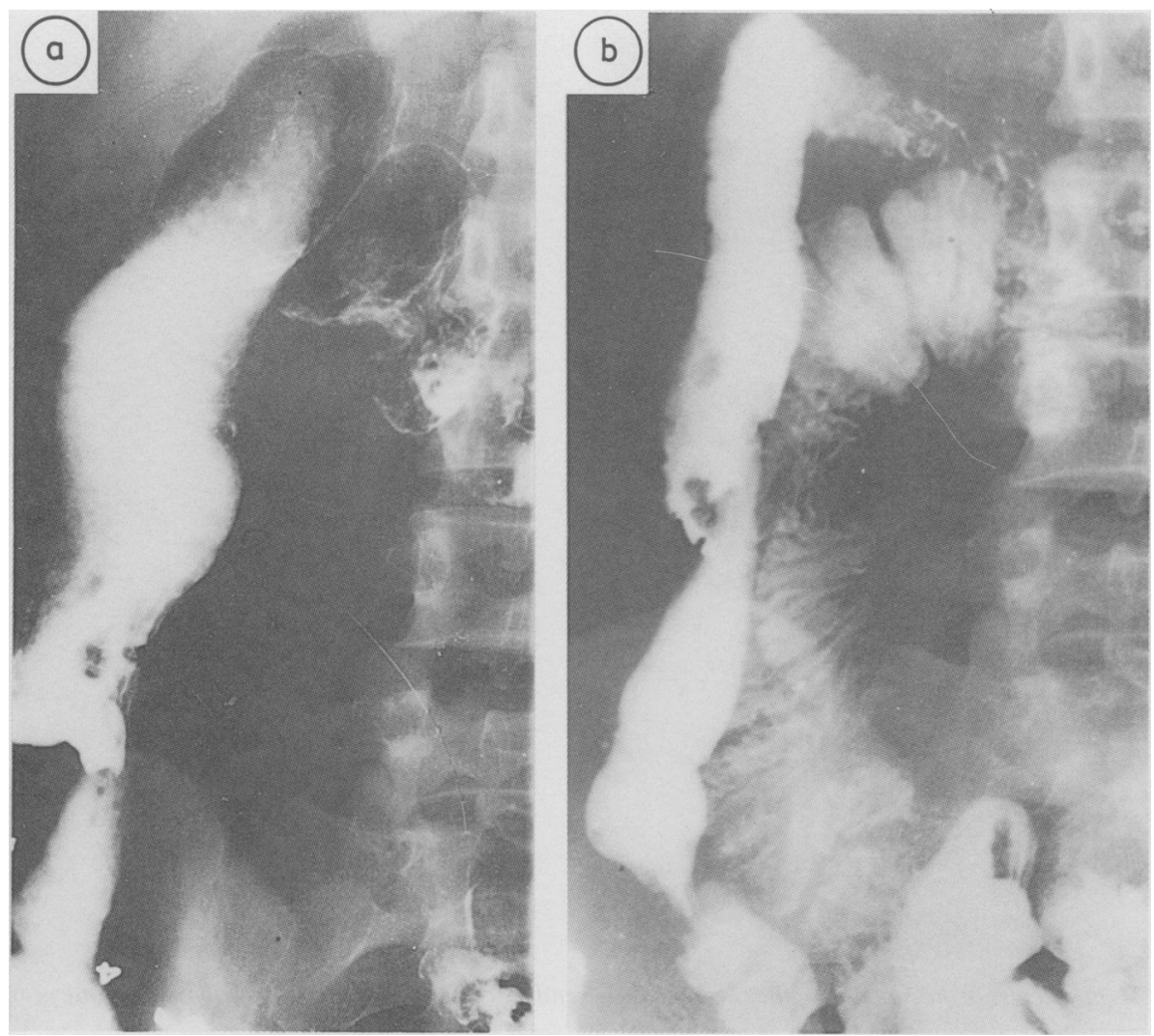

Fig. 4 (a) Gross abnormality of the terminal ileum, caecum and ascending colon. Ileum shows dilatation and there is an area of narrowing between the caecum and the ascending colon. (b) Not much change after one year of treatment and the ileal dilatation persists.

Table Comparison of the clinical profile and length of the radiological defect of patients with complete radiological recovery with those showing persistent defect. No statistical difference was observed with respect to any of the parameters

\begin{tabular}{|c|c|c|}
\hline & $\begin{array}{l}\text { Complete radio- } \\
\text { logical recovery } \\
\text { (I6) }\end{array}$ & $\begin{array}{l}\text { Persistent radio- } \\
\text { logical defect } \\
\text { (7) }\end{array}$ \\
\hline Age (ycars) & $37 \cdot 06 \pm 17 \cdot 33$ & $28 \cdot 71 \pm 12 \cdot 53$ \\
\hline Sex: male/female (ratio) & $10 / 6(1 \cdot 6)$ & $3 / 4(0 \cdot 75)$ \\
\hline \multicolumn{3}{|l|}{ Duration of symptoms (mo) } \\
\hline Mean \pm SD & $16 \cdot 86 \pm 19 \cdot 97$ & $36 \cdot 3 \pm 49 \cdot 4$ \\
\hline Range & $1-48$ & $1 \cdot 5-132$ \\
\hline \multicolumn{3}{|l|}{ Response to treatment } \\
\hline Completely asymptomatic & $14(87 \cdot 5 \%)$ & $5(71 \%)$ \\
\hline Persistence of symptoms & $2(12 \cdot 5 \%)$ & $2(29 \%)$ \\
\hline Duration required for relief & $6.06+232$ & $7.5+3.1$ \\
\hline Pulmonary tuberculosis & $3(19 \%)$ & $2(29 \%)$ \\
\hline $\begin{array}{l}\text { Length of Radiological } \\
\text { defect }(\mathrm{cm})\end{array}$ & & \\
\hline Mean \pm SD $(n)$ & $7 \cdot 9 \pm 3 \cdot 7(8)$ & $11 \cdot 75 \pm 6.85(6)$ \\
\hline
\end{tabular}

whilst receiving antituberculous drugs. During the one year of treatment only three patients required surgery, the remaining $31(91 \%)$ showed significant clinical improvement. Sixteen $(70 \%)$ of the 23 patients in whom a repeat barium study was carried out showed complete resolution of the bowel abnormality; in the remaining seven $(30 \%)$ the defect persisted. Assessment of patients with persistent radiological defect showed that they were younger (mean age: $29 v 37$ years), were more often women $(\mathrm{M}: \mathrm{F}$ ratio $=0.75 v 1.6)$ and had a longer duration of illness (mean $=36.3 v 16.8$ years) than those showing a good radiological response. None of these differences, however, were statistically significant and therefore it is not possible to predict the radiological outcome.

It is interesting to note that despite the persistence of the bowel deformity, the clinical response to treatment of this group was no different from that showing complete radiological recovery. Thus, the 


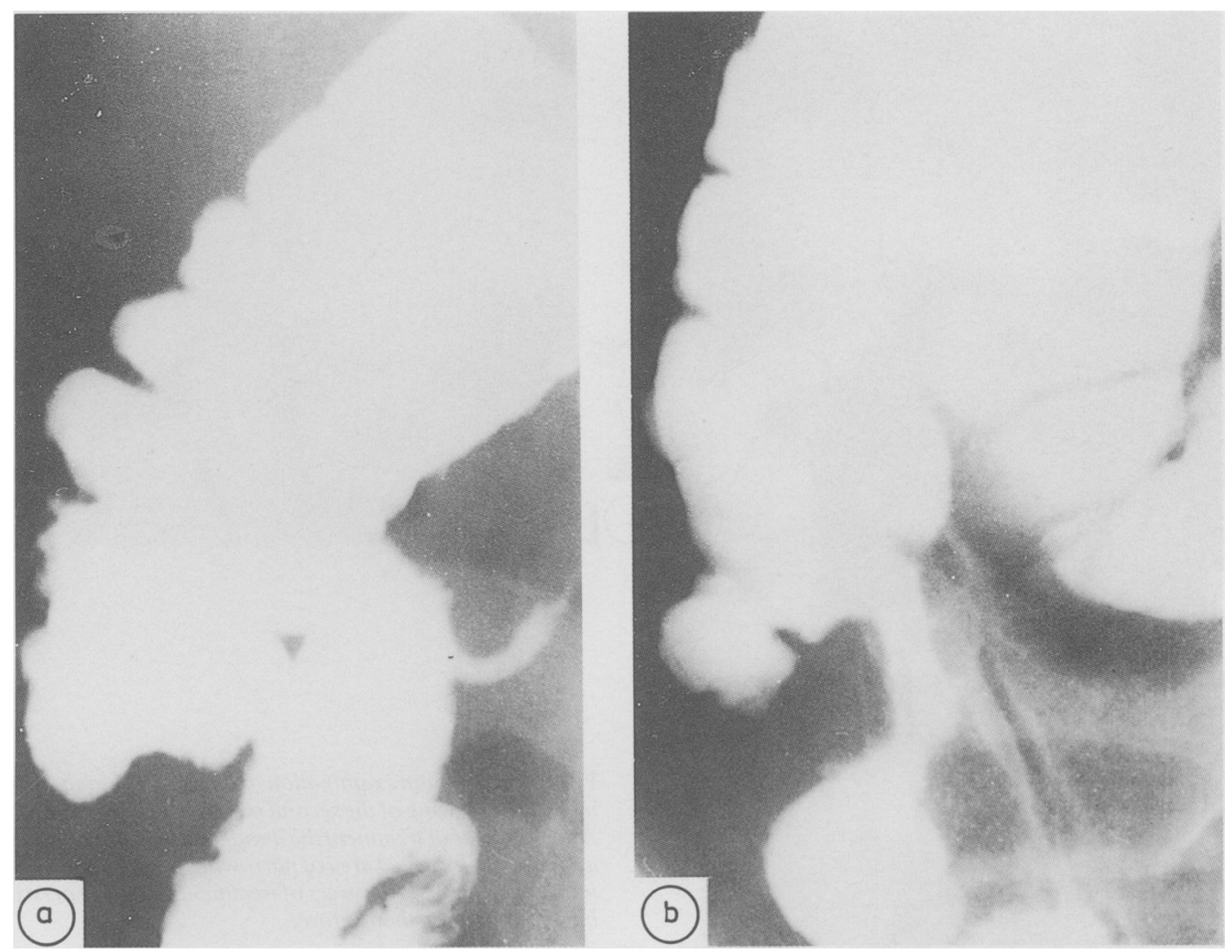

Fig. 5 (a) Mild abnormality of the ileocaecal region. Terminal ileum is dilated and the caecum shows mild deformity with irregularity of the mucosa. (b) After one year of treatment the abnormality has become worse; there is narrowing of the terminal ileum and the caecum is small and contracted.

percentage of patients who became asymptomatic and the duration required for complete relief of symptoms was very similar (Table). One patient in each group developed an episode of subacute intestinal obstruction after completing a full course of antituberculous drugs; both recovered spontaneously and have remained asymptomatic. It is difficult to explain why intestinal obstruction occurred in one patient who did not show any obstructive lesion despite a careful barium examination.

Four $(67 \%)$ of the six non-responders had radiological abnormalities of $12 \mathrm{~cm}$ or more in length compared with only one $(12.5 \%)$ of eight in the responder group. Thus the length of the defect does appear to have some influence on the outcome. It should be noted, however, that two of the nonresponders had stricture lengths of only $6 \mathrm{~cm}$ and $2.5 \mathrm{~cm}$ respectively. Conversely, one patient with an involved segment of $16 \mathrm{~cm}$ in length recovered completely (Fig. 2). Patients with multiple strictures also responded less well to treatment. Of the four such patients, one required surgery and in the remaining three the strictures persisted despite good clinical recovery. Only one $(4 \%)$ of 23 patients showed a worsening of the radiological defect and therefore an increase in the fibrosis and cicatrisation after antituberculous treatment does not appear to be of much significance. The further management of these patients is open to question. In two antituberculous treatment was continued for another year; both showed substantial radiological improvement (Fig. 5). These numbers are too small to draw any definite conclusion but if similar results are obtained in a large number of patients, it may be worthwhile prolonging the treatment in this group.

It is concluded that patients with tuberculous stricture of the bowel presenting with intestinal obstruction can be safely treated with antituberculous drugs. Most $(91 \%)$ became asymptomatic; in about $70 \%$ the stricture disappeared 


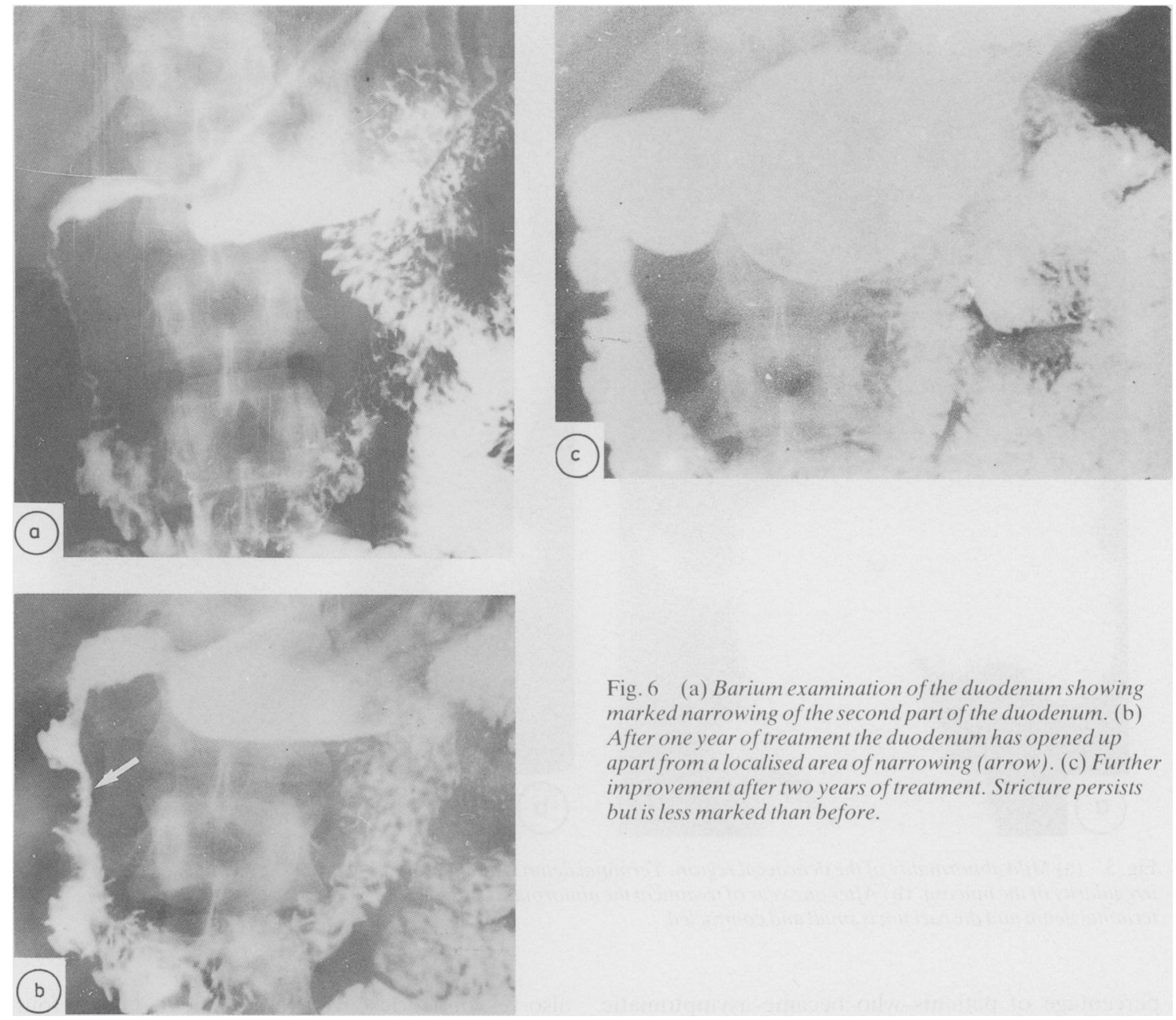

completely and the dilated intestinal loops returned to normal. Patients less likely to respond to medical treatment are those with long strictures $(12 \mathrm{~cm}$ or more in length) and with multiple areas of involvement. We feel that in the management of tubercular stricture surgery should be resorted to only if the patient fails to respond to adequate medical treatment.

\section{References}

1 Chuttani HK. Intestinal tuberculosis. In: Card WI, Creamer B, eds. Modern trends in gastroenterology. London: Butterworths, 197(): 309-27.

2 Pimparkar BD. Abdominal tuberculosis. J Assoc Physcns India 1977; 25: 801-11.

3 Gilinsky NH, Marks IN, Kottler RE, Price SK.
Abdominal tuberculosis: a 10 year review. $S$ Afr Med J $1983 ; 64: 849-57$.

4 Shukla HS, Hughes LE. Abdominal tuberculosis in the 1970's - a continuing problem. Br J Surg 1978; 65: $403-5$.

5 Lambrianides AL, Ackroyd N, Shorey BA. Abdominal tuberculosis. Br J Surg 1980; 67: 887-9.

6 Addison NV. Abdominal tuberculosis - a disease revived. Ann R Coll Surg Engl 1983; 65: 105-11.

7 Palmer KR, Patil DH, Basran GS, Riordan JP, Silk DBA. Abdominal tuberculosis in urban Britain - a common disease. Gut 1985; 26: 1296-305.

8 Marks IN, Kottler RE, Gilinsky NH. Abdominal tuberculosis. In: Jewell D, Shepherd HA, eds. Topics in gastroenterology. Vol 11. Oxford: Blackwell Scientific Publications, 1983: 191-219.

9 Elhence IP. Abdominal tuberculosis as observed by a surgeon. Ind J Tuberc 197(); 26: 59-61. 
10 Bhansali SK. Abdominal tuberculosis. Experience of 300 cases. Am J Gastroenterol 1977; 67: 324-37.

11 Aoki G, Nagasako K, Nakas Y, et al. The fibercolonoscopic diagnosis of intestinal tuberculosis. Endoscopy 1975; 7: 113-21.

12 Bretholz A, Strasser H, Knoblanc M. Endoscopic diagnosis of ileo-caecal tuberculosis. Gastrointest Endosc 1978; 25: 250-1.

13 Breiter JR, Haggar Jean-Jacques. Segmental tuberculosis of the colon diagnosed by colonoscopy. Am J Gastroenterol 1981; 76: 369-73.

14 Tandon HD, Prakash A. Pathology of intestinal tuberculosis and its distinction from Crohn's disease. Gut 1972; 12: 260-9.

15 Anand SS. Hypertrophic ileocaecal tuberculosis in India with a record fifty hemicolectomies. Ann $R$ Coll Surg Engl 1956; 19: 205-22.

16 Parkash A, Sharma LK, Koshal A, Podder PK. Ileocaecal tuberculosis. Aust NZJ Surg 1975; $45: 4$.

17 Anscombe AR, Keddie NC, Schofield PF. Caecal tuberculosis. Gut 1967; 8: 337-43.

18 Howell JS, Knapton PJ. Ileocaecal tuberculosis. Gut 1964; 5: 524-7.
19 Segal I, Ou Timn L, Mirwis J, Hamilton DG, Mannell A. Pitfalls in the diagnosis of gastrointestinal tuberculosis. Am J Gastroenterol 1981; 75: 30-5.

20 Smith A. Streptomycin in treatment of tuberculosis: Council on Pharmacy and Chemistry. JAMA 1948; 138: $548-93$.

21 Sweany H, Lichtenstein MR, Turner GC, et al. Streptomycin treatment of tubercular enterocolitis. Am Rev Tuberc 1949; 60: 576-88.

22 Mason EF, Kridelbaugh WW, Crouch WH, Ward M. Streptomycin in the treatment of tuberculous enteritis, a report of thirty three cases. Am J Med Sci 1949; 217: $28-46$.

23 Jordan CL. DeBakey ME. Complications of tuberculous enteritis occurring during antimicrobial therapy. Arch Surg 1964; 69: 688-93.

24 Weisburg A, Luongo V. Coexistent pulmonary and ileocaecal tuberculosis. NYJ Med 1961; 61: 1965-70.

25 Schofield PF. Abdominal tuberculosis. [Leader]. Gut 1985; 26: $1275-8$.

26 Kasulke RJ, Anderson WJ, Gupta SK, Gliedman ML. Primary tuberculous enterocolitis: report of three cases and review of the literature. Arch Surg 1981; 116: 110-3. 